evidence of participation. Preferred types of CPD activities included attending conferences (71\%) and on line courses (57\%).

Conclusions Whilst the proportion of participants achieving CPD requirements has increased, we must further promote the need to resource and facilitate engagement with CPD, provide relevant learning activities along with continuing development of electronic platforms to facilitate recording of data.

Further research and support is required particularly in relation to the vulnerable group of Non Consultant Hospital Doctors not in training posts.

\section{P246 THE NEW ERA OF MEDICAL EDUCATION}

Aine Fox*, Aisling Smith, Neidin Bussmann, Naomi Mc Callion. Rotunda Hospital, Dublin, Ireland

\subsection{6/archdischild-2019-epa.596}

Background Medical education is an evolving specialty. Educating the doctors of the tomorrow is investment in our own future and should capitalise on all available technologies.

Education is more challenging in recent years due to the increased work load of doctors and increased number of students. It is recognised that students need to be prepared not only from a cognitive and clinical perspective, but also in the affective domain.

Neonatology is a complex area, and students have limited background understanding of the specialty. Many different modalities of teaching have been trialled. The use of video in medical education dates back as far as 1960 (1), and students engage with video technology to enhance their learning experience (2). Video provides an opportunity to give a voice to parents and families which is not always available in clinical interactions.

Aims We aim to assess the impact of video footage of parental NICU experiences on student attitudes towards prematurity.

Methods We introduced video technology into our 2018 undergraduate education programme. Each student was asked to complete a 3 question 'Classroom Assessment Techniques' (CAT) questionnaire before and after watching a video. The video described the 'parental experience' of having an extremely premature infant.

Results and Discussion The completion of the CAT before and after the video was feasible, and $100 \%$ response rate was obtained. Some students elected not to answer each question. After watching the video students had a greater appreciation for the possibility of morbidity and mortality for premature infants. The area that had the greatest impact on the students was the importance of explaining to the parents what they should expect after the baby is born.

Parental anxiety featured strongly as an issue after watching the video. This is an important concept for medical students to grasp and a difficult one to communicate in didactic form. This understanding could improve communication with parents and may promote empathy for families dealing with illness across different specialties.

Conclusion The significance of the patient/parent experience is a concept that is challenging to teach. Appreciating the impact neonatal illness has on both the patient and parent is essential. Providing students with insight into the consequences of prematurity will equip them with holistic skills that will be vital for their future practice. Video has a potential role to play in improving student understanding of these issues, as demonstrated by feasible and user-friendly CATs.

\section{P247 FIRST IMPRESSIONS - THE FIRST 6 MONTHS OF THE OUTCOME BASED MEDICAL EDUCATION PILOT IN BASIC SPECIALIST TRAINING FOR PAEDIATRICS}

${ }^{1}$ Aisling Fitzsimons*, ${ }^{2}$ Aisling Smith, ${ }^{1,2}$ Michael A Boyle. ${ }^{1}$ Rotunda Hospital, Dublin, Ireland; ${ }^{2}$ Royal College of Physicians of Ireland, Dublin, Ireland

10.1136/archdischild-2019-epa.597

Background The Royal College of Physicians of Ireland (RCPI) recently reviewed medical education programmes in light of the international trend towards demonstrable measures of progress. Outcome Based Education (OBE) was selected as the most appropriate for the Irish system and the Paediatric Basic Specialist Training (BST) was chosen to be the pilot scheme. A curriculum was drafted after systematic review and surveying of trainers regarding the importance and frequency of tasks and focus groups. The existing ePortfolio used by BST trainees for recording training was overhauled to reflect the changes made to the curriculum and facilitate recording along the OBE model.

Aim To evaluate the initial experience of Paediatric BST trainees of the OBE model and their interaction with the new ePortfolio.

Methods At the beginning of the term all trainees were required to attend an induction day where the changes and model of training were outlined. Each trainee present also received training on how to use the ePortfolio system and incentives to promote engagement with the system discussed. RCPI first year Paediatric trainees were subsequently surveyed using a surveymonkey $\left({ }^{\circ}\right.$ questionnaire towards the end of their first post of training in December 2018. The individual timelines were also reviewed to assess engagement with the Kaizen ePortfolio.

Results At the end of rotation 33/40 (82.5\%) of trainees had completed a Personal Goal form and $32 / 40$ had completed an End of Post form. During the 6 months 35/40 (87.5\%) had completed a Directly Observed Procedure (DOPs) form with 195 separate DOPs recorded by this group. Trainers have signed off $88 / 195(45 \%)$ of the submitted forms. 12 trainees had no work signed off by their trainers and 2 trainees have not submitted anything to be signed off. $19 / 40$ (47.5\%) of trainees responded to the questionnaire. The majority of responders recognise what is required of them to progress in the programme and the training opportunities available to them in the work place. The ePortfolio was most often accessed monthly to record activities

Conclusion Early data indicates that using OBE is an effective method of facilitating better workplace feedback and evaluation in post graduate training. These findings demonstrate a successful introduction to the workplace and it has been well received. More training of Trainers appears to be needed and support for Trainees in using the ePortfolio and recognising their training opportunities. This will help to further improve the project before rolling out to other specialties. 